\title{
RESFRIAMENTO RÁPIDO DE FORNOS DE CARBONIZAÇÃO
}

\section{DELLY OLIVEIRA FILHO ${ }^{1}$, CARLOS A. TEIXEIRA ${ }^{2}$, JUAREZ DE S. E SILVA ${ }^{3}$, HAMILTON O. REIS ${ }^{4}$, CRISTHIAN L. VOROBIEFF ${ }^{5}$}

\begin{abstract}
RESUMO: A importância dos recursos naturais renováveis no mundo é crescente. No processo produtivo do carvão vegetal, é possível aumentar a eficiência global de transformação da lenha de eucalipto em carvão vegetal. Em processos industriais, o tempo de resfriamento da massa de carvão varia de 6 a 8 dias, com a utilização do resfriamento natural da massa de carvão, sendo que a temperatura para a abertura dos fornos de carbonização é de cerca de $60{ }^{\circ} \mathrm{C}$, e a temperatura inicial da massa de carvão em torno de $480{ }^{\circ} \mathrm{C}$. Sendo assim, foi estudado um sistema de resfriamento de fornos de carbonização utilizando injeção de vapor de água, com o objetivo de reduzir o tempo de resfriamento do carvão. Foram construídos um forno tipo contêiner em escala de laboratório, de dimensões iguais a 3,0 x 2,0 x 1,6 m e um sistema de queima dos gases provenientes da carbonização da lenha, instrumentado com termopares tipo K e um sistema de aquisição de dados, nos Laboratórios de Energia na Agricultura e de Pré-Processamento de Produtos Agrícolas do Departamento de Engenharia Agrícola da Universidade Federal de Viçosa, Viçosa, Minas Gerais. Foi utilizada também uma caldeira para geração de vapor para o resfriamento rápido do forno. $\mathrm{O}$ tempo de resfriamento da massa de carvão foi reduzido em cerca de dois dias pela injeção de vapor de água, quando comparado com o processo de resfriamento natural.
\end{abstract}

PALAVRAS-CHAVE: produção de carvão, utilização de vapor, otimização energética.

\section{FAST COOLING OF MUD OVENS OF CARBONIZATION}

\begin{abstract}
The importance of renewable natural resources in the world is growing. In the production process of charcoal it is possible to increase the overall efficiency of transformation of eucalyptus wood in charcoal. In industrial process cooling time of the charcoal mass varies from 6 to 8 days, using the natural cooling of the charcoal mass, and the temperature for the opening of the mud ovens is about $60{ }^{\circ} \mathrm{C}$ and the initial temperature of the charcoal mass is around $480{ }^{\circ} \mathrm{C}$. Thus, it was studied a system of cooling oven carbonization using injection of steam, with the goal of reducing the cooling time of the charcoal. It was built an oven type container in a test scale with the following dimensions $3.0 \times$ a $2.0 \times 1.6 \mathrm{~m}$, as well as a system burner for exhaustion gases from the wood carbonization, instrumented thermocouples type $\mathrm{K}$ and a data acquisition system at the Laboratories of the Energy Area and Pre Processing of Agricultural Products of the Agricultural Engineering Department of Federal University of Viçosa, Viçosa, Minas Gerais, Brazil. It was built an oven container type on a laboratory scale of dimensions equal to $3.0 \times 2.0 \times 1.6 \mathrm{~m}$ and a firing system of gas exhaustion from the carbonization of wood, instrumented with temperature sensors type $\mathrm{k}$, connected to a data system acquisition. It was also used a boiler to generate steam for the fast cooling of the oven. The cooling time of the coal mass was reduced to about two days by the injection of water vapor when compared to the natural cooling process.
\end{abstract}

KEYWORDS: charcoal production, vapor use, energetic optimization.

\footnotetext{
${ }^{1}$ Prof. Ph.D. DEA/UFV, Av. P.H. Rolfs, UFV, 36570-000, Viçosa, MG, (31) 3899-1897, delly@ufv.br.

${ }^{2}$ Prof. D. S. UFRPE/UAST, carlos.teixeira@uast.ufrpe.br.

${ }^{3}$ Prof. Ph.D., DEA/UFV, juarez@ufv.br.

${ }^{4}$ Técnico DEA/UFV, horeis@ufv.br.

${ }^{5}$ Eng. Agrônomo, M.Sc. crikalao@gmail.com.

Recebido pelo Conselho Editorial em: 22-12-2009

Aprovado pelo Conselho Editorial em: 26-10-2010
} 


\section{INTRODUÇÃOO}

O processo tradicional de produção de carvão vegetal no Brasil possui as seguintes etapas: (i) carga do forno; (ii) fechamento do forno; (iii) ignição; (iv) carbonização (v) resfriamento e (vi) descarga. Usa-se, neste processo, o método de resfriamento natural, que exige de 2 a 10 dias, conforme o tamanho do forno. Esse tempo prolongado de resfriamento influencia diretamente na produção.

Os processos produtivos tendem a se tornar cada vez mais eficientes, para melhorar a utilização dos recursos naturais, dos pontos de vista: ambiental, para minimizar a emissão de poluentes sólidos, líquidos ou gasosos na água, ar ou solo; energético, e econômico (SUES et al., 2010; MAGOSSI, 2007; GASSNER \& MARECHAL, 2008).

A produção de carvão é uma atividade tida como grande poluidora do meio ambiente (MUYLAERT DE ARAÚJO et al., 2009; SILVA et al., 2004). Oferta de biomassa e a sua utilização têm sido objeto de investigação (SILVA et al., 2004; AFONSO JÚNIOR et al., 2006), com o objetivo de tornar a biomassa de lenha viável economicamente e criar também melhores condições de trabalho para o setor e engajar-se nas políticas governamentais desenvolvidas no País para a expansão da utilização de combustíveis renováveis, redução da emissão de poluentes, aumento da eficiência energética dos processos produtivos, considerando ou não as opções de cogeração e geração distribuída de energia elétrica (PIKETTY et al., 2009).

Em empresas produtoras de carvão para siderurgia, o ciclo médio de produção é de 13 dias, com um rendimento gravimétrico médio de 30\%, e um rendimento energético médio de $70 \%$ (BRITO, 1996; MUYLAERT et al., 1999). Destes 13 dias, em média, têm-se: 0,5 h para carga do forno; 4 dias para secagem/carbonização; 8 dias para resfriamento do forno; $0,5 \mathrm{~h}$ para descarga do forno. A temperatura de carbonização é de cerca de $300{ }^{\circ} \mathrm{C}$, e o tempo de carbonização é de cerca de 72 a 96 horas - de 3 a 4 dias (OLIVEIRA et al., 1982; MUYLAERT et al., 1999; TRUGILHO et al., 2005).

No início do processo de carbonização, as entradas de ar frio de combustão vão sendo fechadas de acordo com o avanço da frente de carbonização, e controla-se e mede-se a temperatura de carbonização de forma bastante empírica (MUYLAERT et al., 1999; PINHEIRO et al., 2006). Os gases desprendidos podem ser queimados em uma fornalha, permitindo o aproveitamento desta energia e resolvendo problemas relacionados à emissão de poluentes para o ar (BHATTACHARYA \& SALAM, 2002).

A temperatura de resfriamento mínima para a abertura da porta do forno é de cerca de $60{ }^{\circ} \mathrm{C}$, e o tempo de resfriamento é de cerca de 144 a 168 horas - de 6 a 8 dias em média. A temperatura dos gases de exaustão na chaminé é de cerca de $250{ }^{\circ} \mathrm{C}$ após a saída da fornalha (MUYLAERT et al., 1999; PINHEIRO et al., 2006).

Dentre as possibilidades referentes à otimização do processo de produção de carvão para siderurgia, têm-se: (i) a redução da poluição ambiental; (ii) aproveitamento da energia térmica dos gases queimados para secagem de lenha ou geração de energia elétrica; (iii) aproveitamento da inércia térmica da massa de biomassa carbonizada para geração de energia elétrica e para secagem de lenha a ser carbonizada; (iv) resfriamento rápido do forno de carbonização. Este trabalho tem como objetivo estudar o resfriamento rápido do forno de carbonização com a utilização de injeção de vapor d'água.

\section{MATERIAL E MÉTODOS}

O experimento foi realizado no Departamento de Engenharia Agrícola, nos Laboratórios da Área de Energia na Agricultura e de Pré-Processamento e Armazenamento de Produtos Agrícolas da Universidade Federal de Viçosa, Viçosa, Minas Gerais, Brasil. 
Foi construído um forno de carbonização tipo contêiner, conforme modelo descrito por GIRARD \& FALLOT, 2006; PELAEZ-SAMANIEGO et al., 2008), em escala reduzida, semelhante a fornos encontrados em empresas produtoras de carvão para siderurgia e uma fornalha com parede externa composta de tijolos refratários que estava interligada ao forno de carbonização, com o objetivo de queimar os gases do processo de carbonização. Este forno possui as seguintes medidas internas: $3,0 \times 2,0 \times 1,60 \mathrm{~m}$, com uma flecha de $0,40 \mathrm{~m}$.

Na Figura 1A, mostra-se o protótipo do forno de carbonização e fornalha. Na Figura 1B, apresenta-se a tubulação isolada para a condução do vapor, e a fornalha para queima dos gases provenientes do processo de carbonização. Na Figura 1C, mostra-se o sistema de distribuição de vapor dentro do forno de carbonização, e a Figura 1D a caldeira aquatubular.

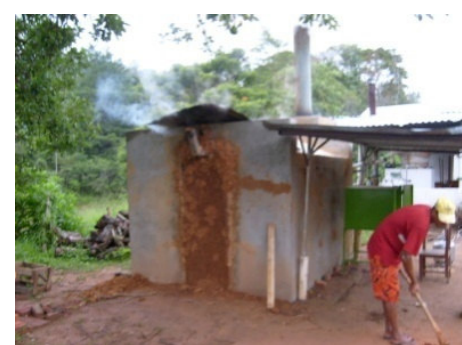

(A)

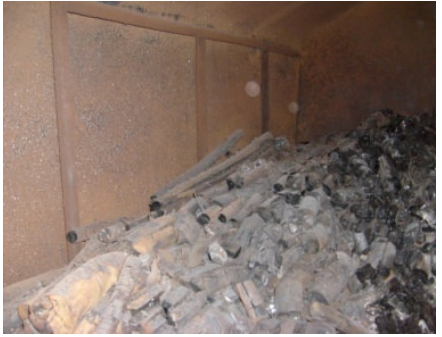

(C)

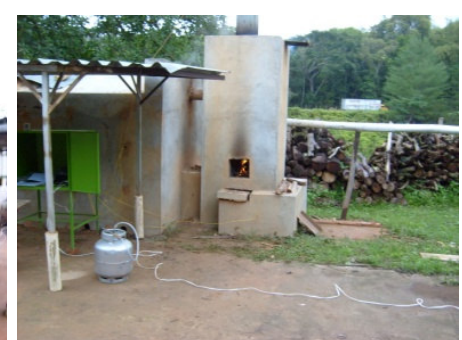

(B)

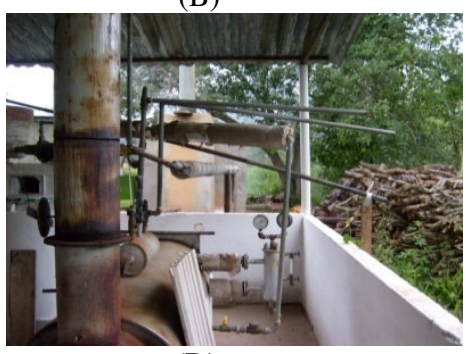

(D)

FIGURA 1. Fotos do experimento e seus componentes: A) protótipo do forno de carbonização e fornalha; B) tubulação isolada para a condução do vapor, e a fornalha para queima dos gases provenientes do processo de carbonização; C) sistema de distribuição de vapor dentro do forno de carbonização, e D) caldeira aquatubular. Pictures of the experiment and its components: A) prototype of charcoal oven and furnace, B) isolated pipe for conducting steam, and the furnace for combustion of gases from the carbonization process, $C$ ) steam distribution system inside the charcoal oven and $D)$ aquatubular boiler.

Foi instalado um sistema de termometria comercial no forno de carbonização. Os termopares utilizados foram do tipo $\mathrm{K}$, e sondas com isolamento mineral de diferentes comprimentos, pois possuem correlação praticamente linear entre a temperatura e o sinal elétrico.

Os termopares eram da Marca Salvi Casagrande, com 2\% de precisão, apropriados para trabalhar de 60 a $1.300{ }^{\circ} \mathrm{C}$. As junções foram feitas pela indústria fornecedora com encapsulamento de aço inox, e com $0,6 \mathrm{~cm}$ de diâmetro externo e $0,4 \mathrm{~cm}$ de diâmetro interno e possuíam comprimento de 0,6 a $1,30 \mathrm{~m}$.

Na Figura 2, mostra-se a vista em corte e a localização dos sensores de temperatura (de 2 a 17), bem como das entradas de ar para carbonização no forno de carbonização. A distribuição dos medidores de temperatura no forno foi feita com o objetivo de acompanhar a frente de carbonização e o andamento do processo de carbonização, em função das aberturas de entrada de ar primário. 


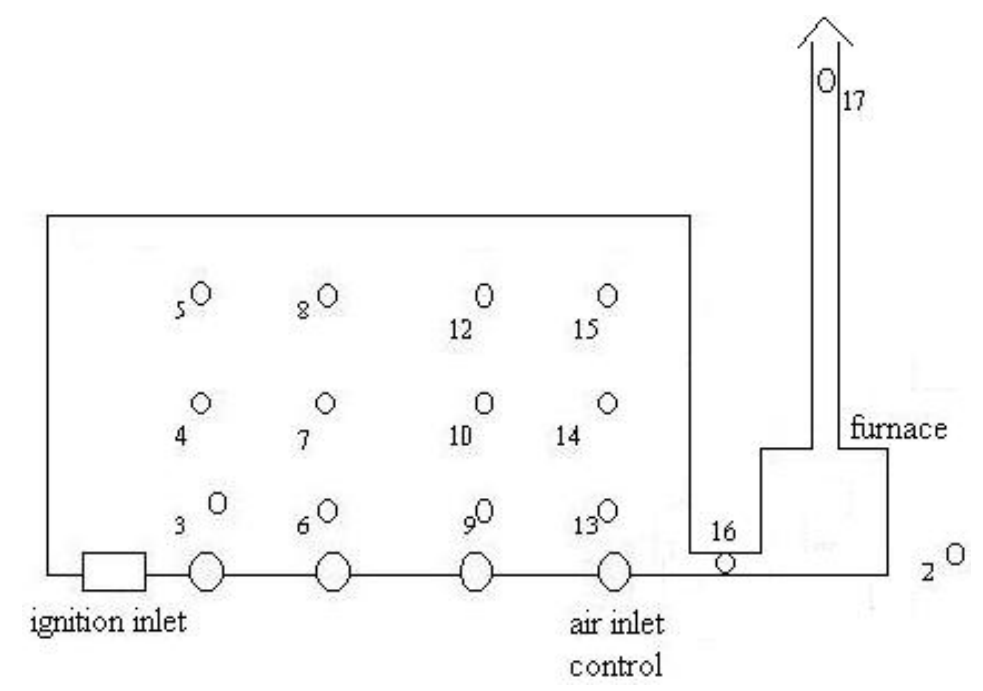

FIGURA 2. Vista em corte da lateral direita do forno de carbonização instrumentado com termopares. Right side cut view of the charcoal mud oven instrumented with thermocouples.

O medidor de temperatura 2 mediu a temperatura do ar ambiente e estava localizado ao lado do equipamento de aquisição de dados, acerca de 3 metros do forno de carbonização, no nível do solo. Os medidores 3; 6; 9 e 13 mediram a temperatura na face interna do forno, na parte inferior do forno, localizados a $0,40 \mathrm{~m}$ do nível do solo. Já os medidores $4 ; 7 ; 10$ e 14 mediram a temperatura na face interna do forno, na parte mediana do forno, localizados a 1,20 m do nível do solo. Os medidores 5; 8; 12 e 15 mediram a temperatura na face interna do forno, na parte superior do forno, localizados a $1,6 \mathrm{~m}$ do solo. O medidor 16 mediu a temperatura no duto entre o forno de carbonização e a entrada da fornalha, estando localizado a $0,30 \mathrm{~m}$ do nível do solo. E o medidor 17 mediu a temperatura dos gases queimados na saída da chaminé, localizado a 4,70 m do nível do solo.

Foram realizados cinco testes de carbonização, sendo que os quatro primeiros testes foram realizados com intuito de: (i) adequar o forno ao processo, por meio de seu revestimento com argamassa de cimento e tela de aço, e (ii) permitir aos autores o conhecimento do processo de carbonização pela identificação do perfil de temperatura do forno e das etapas de carbonização e resfriamento em forno construído em escala reduzida. O quinto teste do resfriamento descrito em detalhes neste artigo foi realizado no período de 15-10-2007 (fechamento do forno) a 24-10-2007 (abertura do forno).

No enchimento do forno, foi utilizado lenha de eucalipto, com umidade média de $25 \%$, b.u. Este teor de umidade é considerado o teor de umidade de lenha seca após o armazenamento ao ar livre. A lenha era desuniforme quanto à forma, com os diâmetros variando de 0,20 a $0,50 \mathrm{~m}$ e com um comprimento médio de 2,6 m.

Foram coletados dados de temperatura em todas as fases de preparo do carvão, secagem da lenha, carbonização e resfriamento da massa de carvão pronto. A cada 30 minutos, foram feitas leituras das temperaturas no forno, utilizando um sistema de aquisição de dados modelo Hydra 2625A, fabricado pela Fluke Corporation, com entradas para 20 pontos controlados, com sensibilidade de $\pm 0,1^{\circ} \mathrm{C}$.

Inicialmente, foi colocado fogo no forno pelos dois orifícios para ignição localizados na porta do forno, um embaixo e o outro em cima, e os outros dois localizados nas laterais do forno. Assim que a chama do forno estava em uma temperatura superior à temperatura de autoignição da lenha, foram fechados esses orifícios e iniciou-se o controle da carbonização pelo fechamento parcial das entradas de ar. $\mathrm{O}$ controle da carbonização obedeceu aos limites de temperatura das etapas endotérmicas e exotérmicas do processo. Desta forma, não foi permitido que a temperatura dentro 
do forno, com a medição feita em sua lateral interna, atingisse os $500{ }^{\circ} \mathrm{C}$, controlando-se, na maior parte do tempo, na faixa de 250 a $350{ }^{\circ} \mathrm{C}$.

Foram feitas as seguintes análises de propriedades físico-químicas do carvão produzido: (i) teor de água (\%); (ii) teor de voláteis (\%); (iii) quantidade de cinzas (\%); (iv) teor de carbono fixo (\%); (v) densidade a granel $\left(\mathrm{kg} \mathrm{m}^{-3}\right)$; (vi) proporção de finos abaixo de 9,52 $\mathrm{mm}(\%)$; (viii) tamanho médio das partículas (mm); (ix) friabilidade (\%); (x) densidade relativa aparente $\left(\mathrm{kg} \mathrm{dm}^{-3}\right)$; (xi) massa específica $\left(\mathrm{kg} \mathrm{dm}^{-3}\right)$; e (xii) porosidade real (\%).

Foram retiradas e analisadas duas amostras de uma fornada, que foram submetidas ao processo de resfriamento natural, que serviram como testemunhas para comparação com a massa de carvão resfriada artificialmente, ou seja, pelo sistema de injeção de vapor de água. As análises foram realizadas nos laboratórios da Companhia Agrícola Florestal (CAF), localizados no município de Martim Campos - MG, especializados em análises da qualidade de carvão vegetal.

\section{RESULTADOS E DISCUSSÃO}

No momento do resfriamento da massa de carvão, foi utilizada a injeção de vapor d'água. $\mathrm{O}$ resfriamento foi feito dentro dos seguintes limites de temperatura: $480{ }^{\circ} \mathrm{C} \mathrm{a} 112^{\circ} \mathrm{C}$.

Nas Figuras 3; 4 e 5, mostra-se a variação de temperatura dentro do forno, considerando o período de secagem da lenha, carbonização e resfriamento rápido da massa de carvão, com a utilização da injeção de vapor d'água.

Na Figura 3, apresenta-se a variação de temperatura na parte inferior do forno, sendo que, nas primeiras quarenta e cinco horas do processo de pirólise, houve a secagem da lenha, e nas últimas 23 horas, carbonização da lenha.

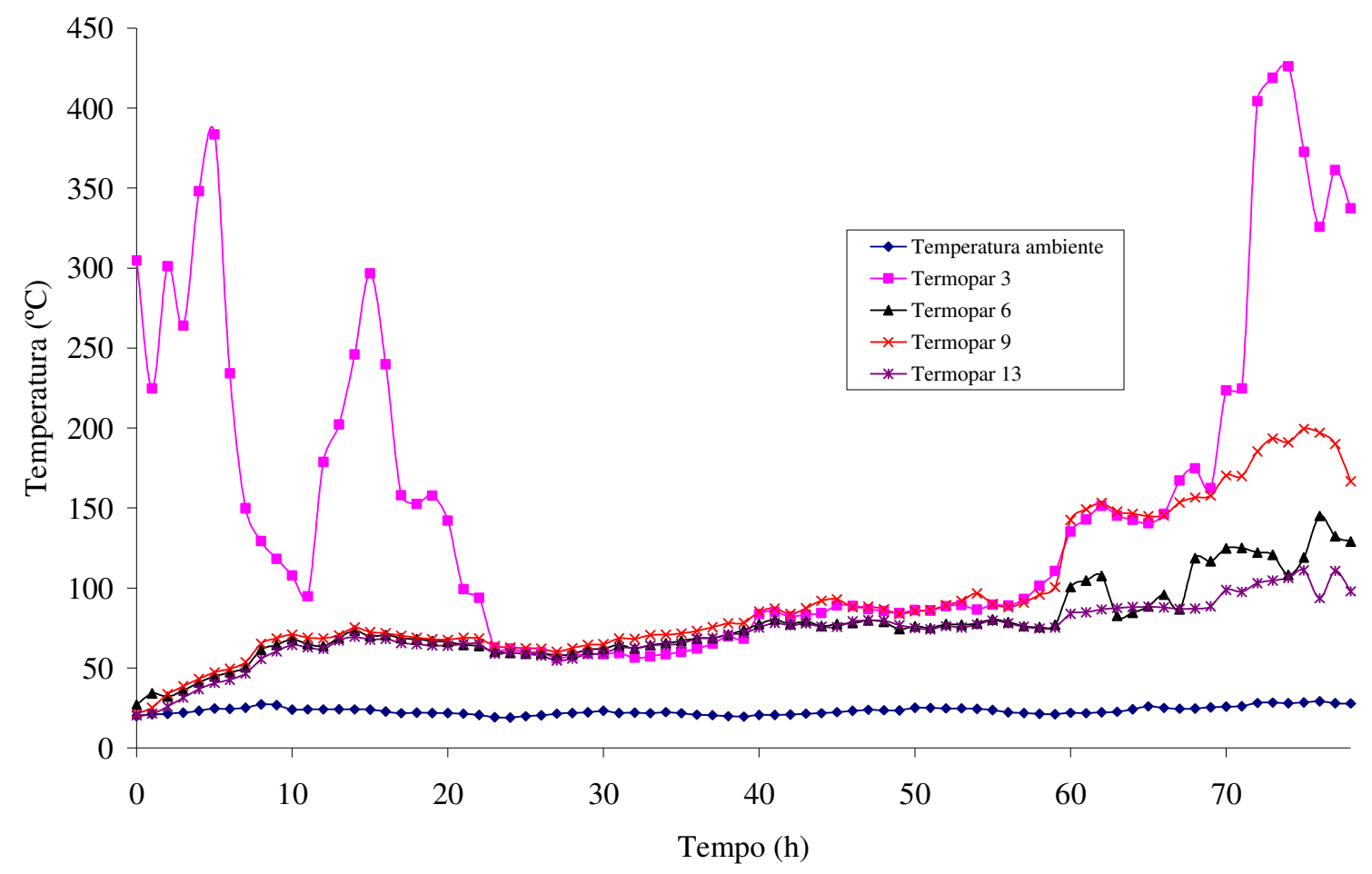

FIGURA 3. Variação de temperatura dentro do forno em relação ao tempo, nos termopares 2; 3; 6; 9 e 13. Temperature variation inside the oven in relation to time in thermocouples $2,3,6,9$ and 13 .

Na Figura 4, mostra-se a variação de temperatura nos medidores de temperatura instalados na parte mediana do forno, sendo que, nas primeiras quarenta e cinco horas do processo, houve a 
secagem da lenha, e nas últimas 23 horas, carbonização da lenha, assim como na parte inferior do forno.

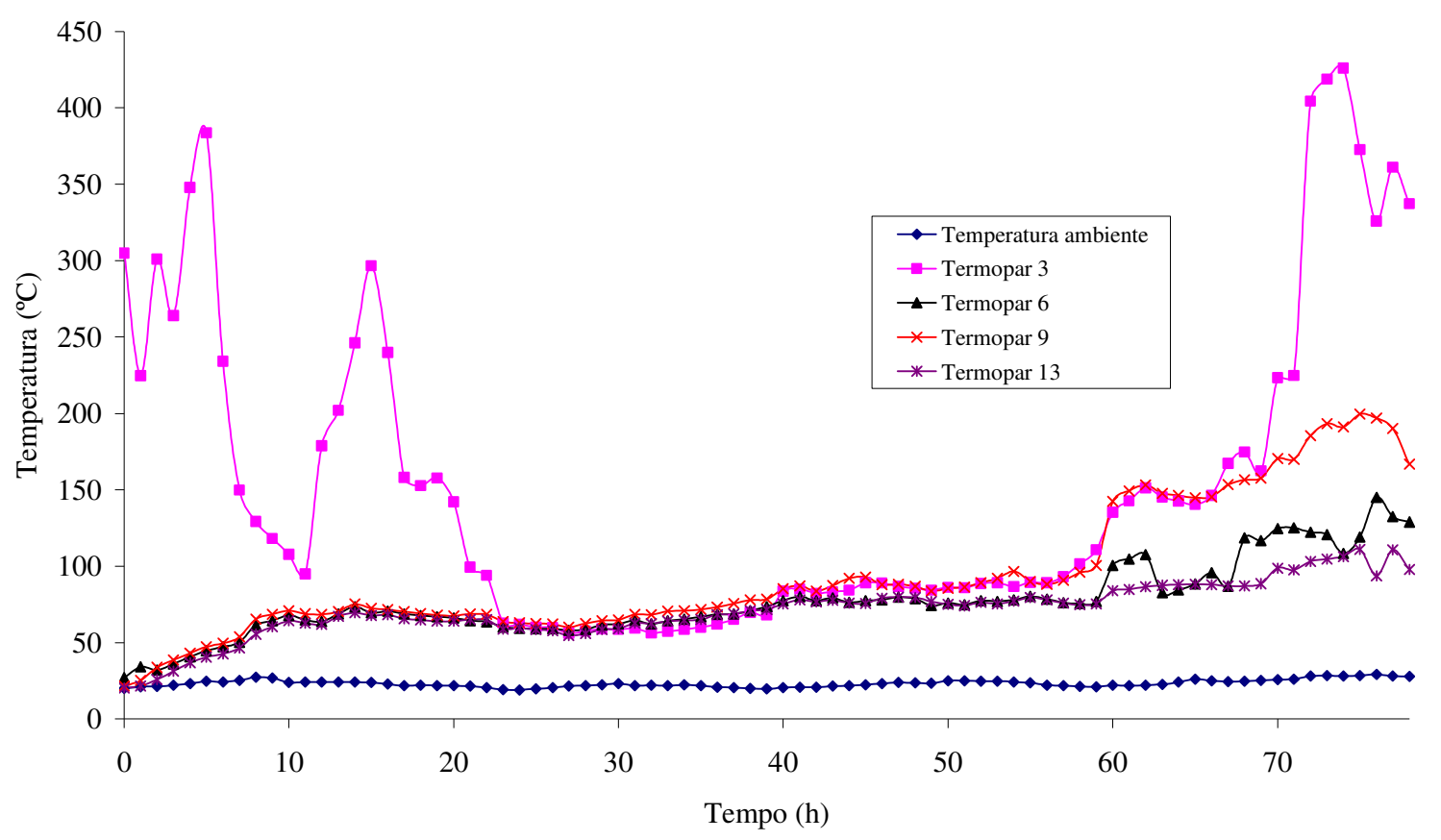

FIGURA 4. Variação de temperatura dentro do forno em relação ao tempo, nos termopares 2; 4; 7; $10 \mathrm{e} 14$. Temperature variation inside the oven in relation to time in thermocouples 2, 4, 7, 10 and 14.

Na Figura 5, mostra-se a variação de temperatura nos termopares instalados na parte superior da pilha de lenha, sendo que, nas primeiras quarenta horas do processo, houve a secagem da lenha, e nas últimas 28 horas, a carbonização.

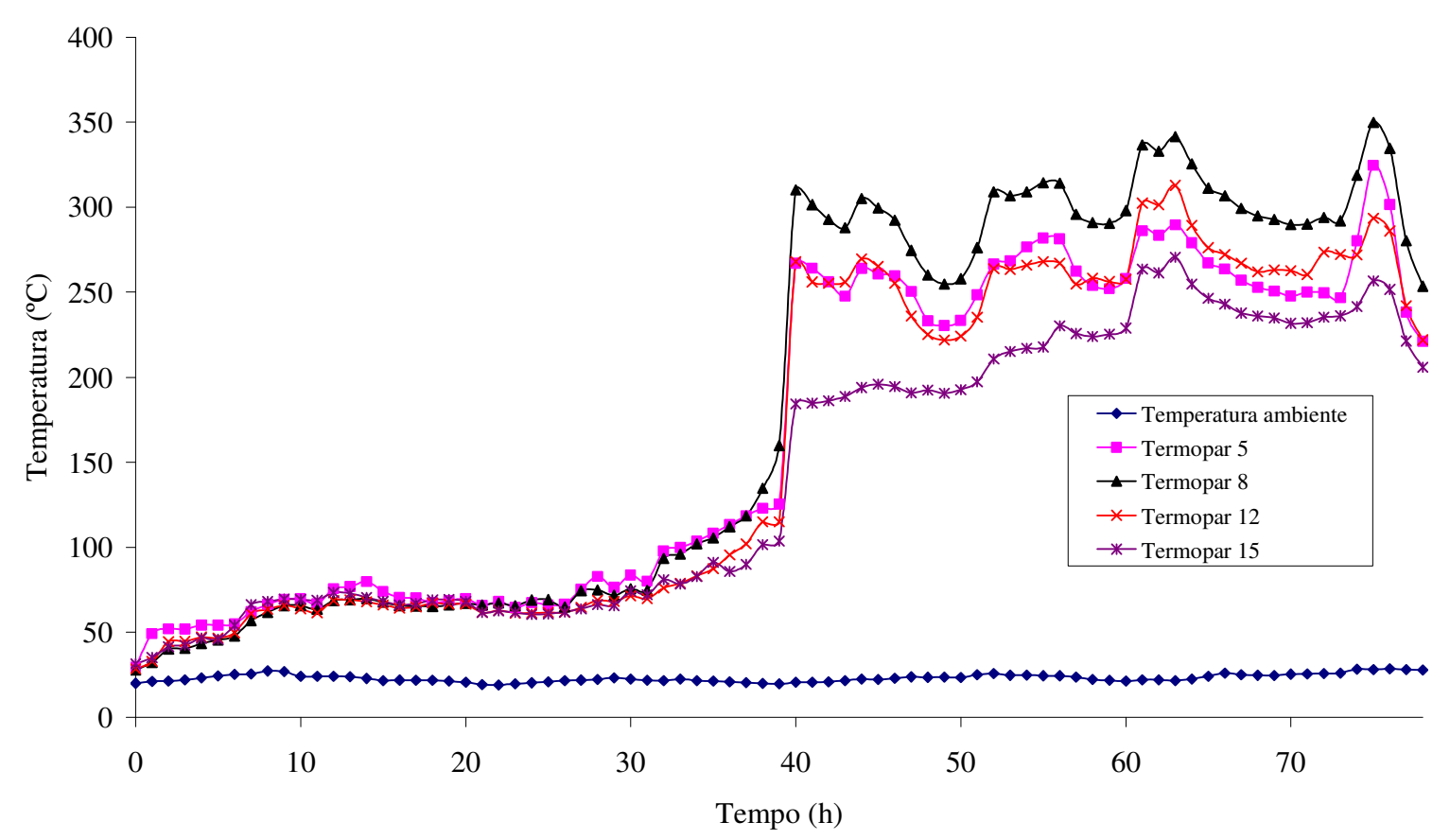

FIGURA 5. Variação de temperatura dentro do forno em relação ao tempo, nos termopares 2; 5; 8; $12 \mathrm{e} 15$. Temperature variation inside the oven in relation to time in thermocouples $2,5,8,12$ and 15 . 
De acordo com as Figuras 3; 4 e 5, observa-se que a frente de carbonização se deslocou da parte superior da pilha de lenha para a parte inferior, e no sentido da porta do forno para o ponto de escoamento da fumaça, na base da chaminé.

A Figura 6 mostra o processo de resfriamento forçado da massa de carvão e da estrutura do forno em relação ao comportamento do decaimento da temperatura com o tempo, em todos os medidores de temperatura instalados no forno.

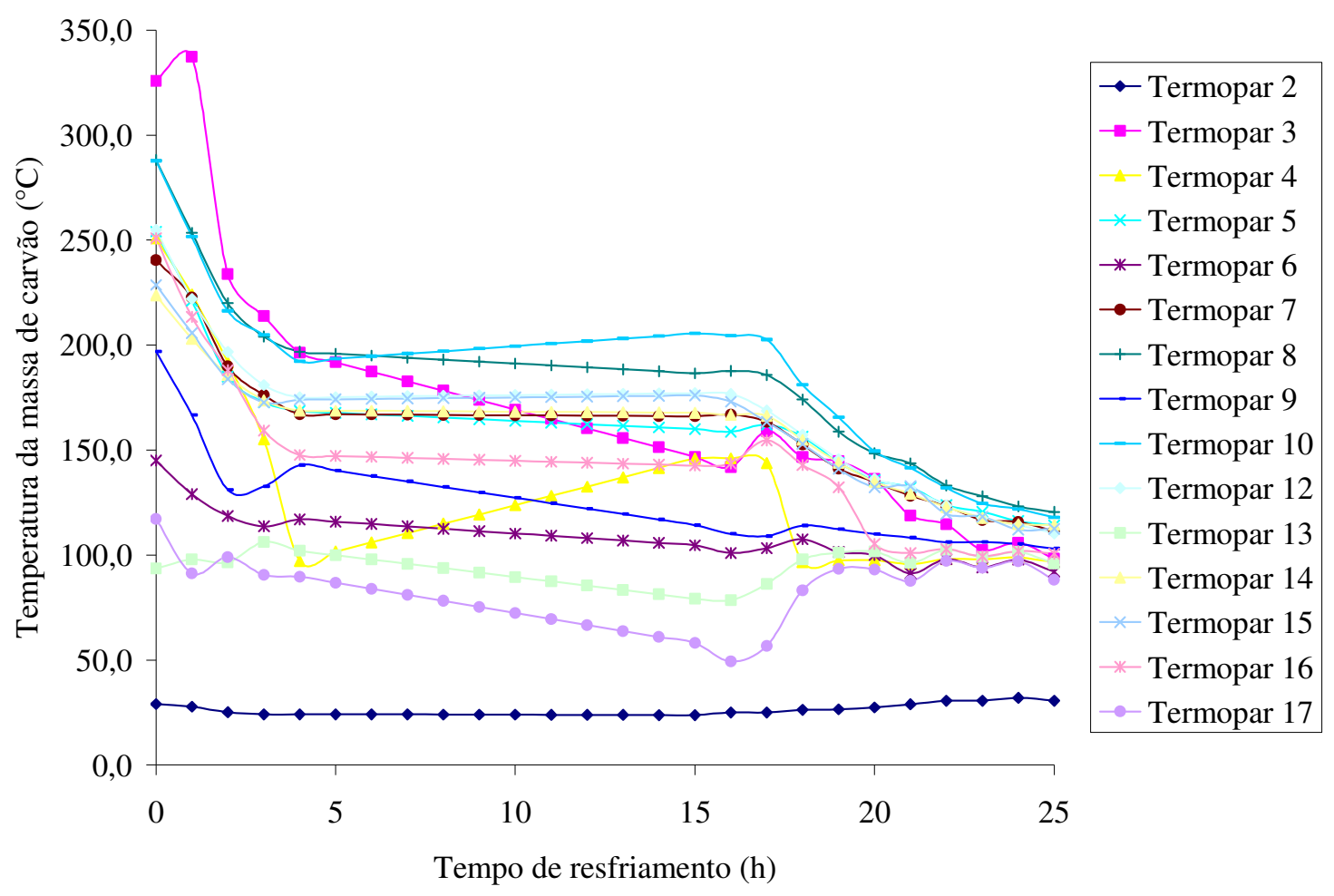

FIGURA 6. Variação de temperatura dentro do forno em relação ao tempo, em todos os termopares, no processo de resfriamento. Temperature variation inside the oven in respect to time in all thermocouples in the cooling process.

Cabe lembrar que, no primeiro dia do processo de resfriamento forçado, houve apenas quatro horas de resfriamento forçado, com a utilização de injeção de vapor, na base da massa de carvão. Depois, houve um período de treze horas de resfriamento natural do forno de carbonização, no período da noite. A operação de resfriamento com aplicação do vapor d'água foi recomeçada no dia seguinte, por um período de 8 horas e meia. Portanto, houve apenas 12 horas de resfriamento forçado e 13 horas de resfriamento natural. Ao final das 12 horas de injeção de vapor no forno de carbonização, as temperaturas nos medidores de temperatura aproximavam-se de $112^{\circ} \mathrm{C}$. Neste instante, encerrou-se o resfriamento forçado e iniciou-se o resfriamento natural, outra vez, por cerca de 24 horas até a massa de carvão atingir a temperatura de abertura do forno em cerca de $60^{\circ} \mathrm{C}$.

O controle do encerramento da carbonização e do resfriamento foi feito inicialmente, fechando-se todas as entradas de oxigênio do forno. Com o início do processo de injeção de vapor, foram abertos os orifícios entrada de ar para carbonização localizados nas paredes laterais ao lado dos pontos de termometria 13 e 15, por onde o fluxo da mistura gases da carbonização e do vapor d'água saiu, resfriando a massa de carvão lentamente.

Foi feita a realização de testes no carvão produzido, considerando este forno com sistema de resfriamento natural da massa de carvão.

Nas Tabelas 1 e 2, mostram-se os resultados dos testes com o carvão produzido como testemunha, ou seja, com resfriamento natural em duas repetições. O resfriamento em ambos os testes foi feito considerando o período do final da carbonização até a abertura do forno. 
TABELA 1. Dados técnicos da produção de carvão vegetal com resfriamento natural. Technical charcoal production data with natural cooling.

\begin{tabular}{lr}
\hline Amostra 1 - Carvão com resfriamento natural & \\
Parâmetros avaliados & Valor \\
\hline Umidade (\%) & 4,87 \\
Voláteis (\%) & 21,81 \\
Cinzas (\%) & 0,88 \\
Carbono fixo (\%) & 77,31 \\
Densidade a granel $\left(\mathrm{kg} \mathrm{m}^{-3}\right)$ & 202,11 \\
Proporção de finos $<9,52 \mathrm{~mm}(\%)$ & 24,64 \\
Tamanho médio das partículas $(\mathrm{mm})$ & 31,20 \\
Friabilidade $(\%)$ & 45,00 \\
Umidade (\%) & 4,31 \\
Densidade relativa aparente $\left(\mathrm{kg} \mathrm{dm}^{-3}\right)$ & 0,42 \\
Densidade relativa $\left(\mathrm{kg} \mathrm{dm}^{-3}\right)$ & 1,44 \\
Verdadeira porosidade $(\%)$ & 70,87 \\
\hline
\end{tabular}

TABELA 2. Dados técnicos da produção de carvão vegetal com resfriamento artificial, por meio de vapor d'água. Technical charcoal production data with artificial cooling through water vapor.

\begin{tabular}{lr}
\hline \multicolumn{2}{l}{ Amostra 2 - Carvão com resfriamento artificial, por meio de vapor d'água } \\
Parâmetros avaliados & Valor \\
\hline Umidade (\%) & 4,81 \\
Voláteis (\%) & 27,05 \\
Cinzas (\%) & 0,69 \\
Carbono fixo (\%) & 72,27 \\
Densidade a granel $\left(\mathrm{kg} \mathrm{m}^{-3}\right)$ & 180,35 \\
Proporção de finos $<9,52 \mathrm{~mm}(\%)$ & 17,04 \\
Tamanho médio das partículas $(\mathrm{mm})$ & 32,05 \\
Friabilidade $(\%)$ & 52,44 \\
Umidade $(\%)$ & 4,87 \\
Densidade relativa aparente $\left(\mathrm{kg} \mathrm{dm}^{-3}\right)$ & 0,32 \\
Densidade relativa $\left(\mathrm{kg} \mathrm{dm}^{-3}\right)$ & 1,47 \\
Verdadeira porosidade $(\%)$ & 78,43 \\
\hline
\end{tabular}

No primeiro teste, foi enfornada uma massa de lenha de Eucalipto pellita igual a $3.619 \mathrm{~kg}$, pesada em balança rodoviária com precisão de um quilograma do fabricante Filizola. A massa de carvão produzida foi igual a $728 \mathrm{~kg}$ de carvão e $90,5 \mathrm{~kg}$ de moinha de carvão. De acordo com a Tabela 1, pelos índices encontrados em comparação com carvoarias que produzem carvão para siderurgia, a qualidade é satisfatória. Cabe lembrar que este carvão não foi submetido a resfriamento rápido.

No segundo teste, foi enfornada uma massa de lenha de Eucalipto pellita igual a $3.480 \mathrm{~kg}$, pesada em balança rodoviária com precisão de um quilograma. A massa de carvão produzida foi igual a $785 \mathrm{~kg}$ de carvão e 83,6 kg de moinha de carvão. De acordo com a Tabela 2, pelos índices encontrados em comparação com carvoarias que produzem carvão para siderurgia, a qualidade, também, é satisfatória. Cabe lembrar que este carvão foi submetido a resfriamento com vapor d'água.

Sendo assim, houve: (i) 78 horas de secagem e carbonização da lenha; (ii) 14 horas de resfriamento com injeção de vapor; e (iii) cerca de 37 horas de resfriamento natural. Neste teste, uma fornada de carvão foi realizada em torno de 128 horas, cerca de 6 dias. 
Com a redução do tempo de produção de carvão, a instalação produtora poderá maximizar a utilização dos fornos, dos pátios de armazenamento de lenha, de máquinas, entre outros. No entanto, a utilização deste carvão produzido com resfriamento a vapor deve ser avaliada.

Outro aspecto a ser discutido foi a queima dos gases advindos do processo de carbonização. Estes gases aquecidos saíam do forno de carbonização e eram forçados a passar pela câmara de combustão da fornalha.

Outro aspecto interessante a ser considerado é que, quando os tijolos refratários da fornalha de queima dos gases estavam aquecidos e com um mínimo de combustível em chama na grelha da fornalha, os gases do processo de combustão que ali passavam, tinham sua densidade reduzida, aumentando assim a velocidade de tiragem da chaminé da fornalha, possibilitando controlar a aceleração ou a redução da velocidade de produção de carvão.

Na grelha da câmara de combustão da fornalha, os gases foram queimados com a utilização de resíduos de lenha até o ponto de autoignição. A autoignição acontecia quando os níveis de gases combustíveis eram altos, ocorrendo, normalmente, em torno de 24 horas após o acendimento do forno.

\section{CONCLUSÕES}

A técnica da injeção de vapor d'água para o resfriamento de fornos de carbonização de $480^{\circ} \mathrm{C}$ até $112{ }^{\circ} \mathrm{C}$ reduziu o tempo em cerca de 14 horas, ou seja, cerca de $50 \%$ do tempo normal de resfriamento natural. Essa diminuição do tempo de resfriamento representa um aumento da eficiência de utilização dos fornos de carbonização, consequentemente, aumentando a produção de carvão vegetal por instalação.

\section{AGRADECIMENTOS}

Os autores são gratos pelo financiamento desta pesquisa por parte da FAPEMIG, Fundação de Amparo à Pesquisa do Estado de Minas Gerais, da CAF, Companhia Agrícola Florestal, do CNPq, Conselho Nacional de Desenvolvimento Científico e Tecnológico, e da CAPES, Coordenação de Aperfeiçoamento de Pessoal de Nível Superior.

\section{REFERÊNCIAS}

AFONSO JÚNIOR, P.C.; OLIVEIRA FILHO, D.; COSTA, D.R. Viabilidade econômica de produção de lenha de eucalipto para secagem de produtos agrícolas. Engenharia Agrícola, Jaboticabal, v.26, n.1, p.28-35, 2006. Disponível em: < http:/

/www.scielo.br/scielo.php?script=sci_arttext\&pid=S010069162006000100004\&lng=en\&nrm=iso $>$.

BHATTACHARYA, S.C.; SALAM, P.A. Low greenhouse gas biomass options for cooking in the developing countries. Biomass \& Bioenergy, v.22, n.4, p.305-317, 2002. Disponível em: <<Go to ISI $>: / / 000174865100008>$.

BRITO, O.C. Carvão vegetal no Brasil: Gestões econômica e ambiental. Estudos Avançados, São Paulo, v.4, n.9, p.221-228, Aug. 1996.

GASSNER, M.; MARECHAL, F. Thermo-economic optimisation of the integration of electrolysis in synthetic natural gas production from wood. Energy, v.33, n.2, p.189-198, feb. 2008. I

Disponível em: < <Go to ISI $>$ ://000253574700011 >.

GIRARD, P.; FALLOT, A. Review of existing and emerging technologies for the production of biofuels in developing countries. Energy for Sustainable Development, v.10, n.2, p.92-108, 2006. Disponível em: <http://www.sciencedirect.com/science/article/B94T4-4V9PDF9-

B/2/f337b3acb9d88c66226dadecf1bbb2ab $>$. 
MAGOSSI, D.C. A produção florestal e a industrialização de seus resíduos na região de Jaguariaíva - Paraná. 2007. 88 f. Dissertação (Mestrado em Engenharia Florestal) - Universidade Federal do Paraná, Curitiba, 2007.

MUYLAERT DE ARAÚJO, M.S.; SILVA, C.; CAMPOS, C.P.D. Land use change sector contribution to the carbon historical emissions and the sustainability--Case study of the Brazilian Legal Amazon. Renewable and Sustainable Energy Reviews, v.13, n.3, p.696-702, 2009. Disponível em: <http://www.sciencedirect.com/science/article/B6VMY4RFC8NK1/2/b597002ae6fc8038f8b2fcee588 e 4bc9 >.

MUYLAERT, M.S.; SALA, J.; DE FREITAS, M.A.V. The charcoal's production in Brazil process efficiency and environmental effects. Renewable Energy, v.16, n.1-4, p.1.037-1.040, jan-apr 1999. Disponível em: <Go to ISI $>/ / / 000076229000090>$.

OLIVEIRA, J. B. VIVACQUA FILHO, A.;MENDES, M.G.; GOMES, P. A. Caracterização e otimização do processo de fabricação de carvão vegetal em fornos de alvenaria. Belo Horizonte: CETEC, 1982. p.63-102 (Série de publicações Técnicas).

PELAEZ-SAMANIEGO, M. R.; GARCIA-PEREZ, M.; CORTEZ, L. A. B.; ROSILLO-CALLE, F.; MESA, J. Improvements of Brazilian carbonization industry as part of the creation of a global biomass economy. Renewable \& Sustainable Energy Reviews, v.12, n.4, p.1.063-1.086, may 2008. Disponível em: < <Go to ISI $>$ ://000255422100005 >.

PIKETTY, M. G.; WICHERT, M.; FALLOT A.; AIMOLA L. Assessing land availability to produce biomass for energy: The case of Brazilian charcoal for steel making. Biomass \& Bioenergy, v.33, n.2, p.180-190, Feb 2009. Disponível em: <<Go to ISI >://000263995200003 >.

PINHEIRO, P.C.C.; VIANA, E.; REZENDE, M.E.A.; SAMPAIO, R.S. A produção de carvão vegetal. Belo Horizonte: edição do autor, 2006.

SILVA, J.N.; CARDOSO SOBRINHO, J.; SAIKI, E.T. Utilização de biomassa na secagem de produtos agrícolas via gaseificação com combustão adjacente dos gases produzidos. Engenharia Agrícola, Jaboticabal, v.24, n.2, p.405-411, 2004. Disponível em:

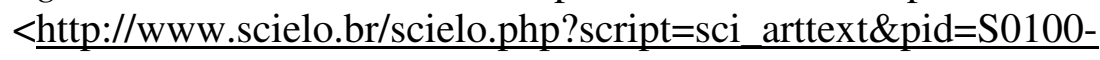
$\underline{69162004000200020 \& \operatorname{lng}=\text { en\&nrm=iso }}>$.

SUES, A.; JURASCÍK, M.; PTASINSKI, K. Exergetic evaluation of 5 biowastes-to-biofuels routes via gasification. Energy, v.35, n.2, p.996-1.007, 2010.

TRUGILHO, P. F. SILVA, J.R.M.; MORI, F.A.M.; LIMA, J.T.; MENDES, L.M.; MENDES, L.F.B. Rendimentos e características do carvão vegetal em função da posição radial de amostragem em clones de Eucalyptus. Cerne, Lavras, v.11, n.2, p.178-186, 2005. 